\title{
Intestinal Tuberculosis versus Crohn's Disease: Evaluating the Role of Computed Tomography Enterography in Differentiating the Two
}

\author{
Saniya Muslim Meenu Bagarhatta \\ ${ }^{1}$ Department of Radiodiagnosis, SMS Medical College and Attached \\ Group of Hospitals, Jaipur, Rajasthan, India
}

\begin{abstract}
Address for correspondence Saniya Muslim, MD, Department of Radiodiagnosis, SMS Medical College and Attached Group of Hospitals, 108, Family Hostel, Gangwal Park, JLN Road, Jaipur 302001, Rajasthan, India (e-mail: drsaniya91@gmail.com).
\end{abstract}

\begin{abstract}
Intestinal tuberculosis (ITB) and Crohn's disease (CD) are chronic inflammatory bowel disorders that are frequently misdiagnosed due to overlapping clinical, radiologic, endoscopic, and histologic resemblance. Recent trends indicate a change in the epidemiology of inflammatory bowel diseases, with previously low-incidence areas now reporting a continuous rise in incidence. The rising incidence of $C D$ in countries such as India where TB continues to be endemic has made the differentiation of these

Keywords

- Crohn's disease

- computed tomography enterography

- intestinal tuberculosis two disorders a diagnostic challenge. Misdiagnosis leads to delays in initiating effective therapy with increased morbidity and mortality, hence the importance of making an accurate diagnosis at the earliest possible stage. This study aimed to evaluate the diagnostic value of computed tomography enterography findings in the differential diagnosis between ITB and CD.
\end{abstract}

\section{Introduction}

Crohn's disease (CD) and intestinal tuberculosis (ITB) are chronic granulomatous diseases that due to their overlapping clinical, endoscopic, and pathological findings are difficult to differentiate. ${ }^{1,2}$

The disease course of ITB is quite different from that of CD. ITB can be completely cured if diagnosed early and treated properly. However, $\mathrm{CD}$ is prone to recurrences, hence lies the importance of making accurate diagnosis at the earliest possible stage. ${ }^{3.4}$

Plain abdominal radiographs have little role in making a diagnosis of ITB or CD. Chest radiograph may show features of active or healed tuberculosis in up to $15 \%$ of patients. ${ }^{5}$

Barium meal follow-through (BMFT) may show thickening of mucosal folds, ulcerations, strictures, dilatation, and clumping of bowel loops in both these diseases and provides information on bowel motility. ${ }^{6,7}$ However, this study takes a long time, is two dimensional, and provides no extraluminal information.

Barium enteroclysis has a higher sensitivity for detecting mucosal abnormalities and strictures. ${ }^{8,9}$ It achieves good distension of the small bowel loops to enable the detection of early abnormalities. Its disadvantages include discomfort to the patient due to the nasojejunal tube and active bowel distension, radiation and lack of information regarding the bowel wall, and extraintestinal manifestations.

Ultrasonography (USG) is a simple and widely available modality without the effects of ionizing radiation; however, it is not very useful in the differentiation of ITB from CD. The other limitations include operator dependence, bowel gas, obesity, and long scan times required for complete evaluation.

Computed tomography (CT) is often the initial investigation performed for the evaluation of suspected bowel pathology. The positive contrast only depicts bowel wall thickening, stricture, and dilatation, but not mucosal abnormality, and does not provide adequate distension of the bowel. CT enteroclysis is performed after inserting a nasojejunal tube and injecting neutral contrast agent to provide adequate distension of the small bowel. ${ }^{10}$ The tube and active bowel distension often causes discomfort to the patient.

CT enterography (CTE) combines the improved spatial and temporal resolution of multiple detector row $\mathrm{CT}$ with
License terms

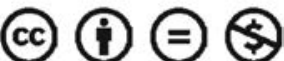


large volumes of ingested neutral enteric contrast material to permit visualization of the small bowel wall and lumen. CTE can image the entire gastrointestinal tract and characterize extraintestinal manifestations, such as the lymph nodes, mesenteric changes, mural stratification, fibrofatty proliferation, fistulae, abscesses, adjacent organ involvement, and ascites that have an important role in differentiating CD and ITB.

Magnetic resonance enterography (MRE) recently has been gaining in popularity, especially for follow-up imaging of pediatric and young patients with established inflammatory conditions of the small bowel. ${ }^{11,12}$ The lack of ionizing radiation is an advantage of MRE over CTE, especially when evaluating patients with known renal dysfunction. However, MRE is time consuming, expensive, and has variable reproducibility regarding image quality as compared with CTE.

\section{Technique}

Patients are requested to abstain from all food and drink for 4 hours prior to scanning. Bowel is distended passively by ingesting neutral oral contrast agents, which include water, polyethylene glycol solution, or VoLumen (low-density barium in sorbitol), adding osmotic agents such as mannitol, sorbitol, or polyethylene glycol improves bowel distension. ${ }^{13,14} \mathrm{We}$ used mannitol (20\%) that is prepared by diluting $400 \mathrm{~mL}$ of mannitol in $1,500 \mathrm{~mL}$ of water. This solution is ingested over 45 minutes, and the patient is scanned subsequently. The last 250 to $300 \mathrm{~mL}$ is ingested on table, just prior to scanning for gastric distension, and the patient is made to lie in right lateral decubitus for 3 to 5 minutes; $20 \mathrm{mg}$ Buscopan is administered intravenously (IV) immediately prior to scanning to reduce bowel peristalsis. ${ }^{15}$ Scanning was done in enteral phase acquired at 45 seconds, and bowel wall shows maximal enhancement in this phase ${ }^{16}$ using 128 -slice MDCT scanner (Philips Ingenuity, Suzhou, China) and $1.5 \mathrm{~mL} / \mathrm{kg}$ of iohexol (Omnipaque $350 \mathrm{mg} / \mathrm{mL} 50 \mathrm{~mL}$, GE Health Care, Shanghai, China). Summary of technique ${ }^{15}$ is mentioned in - Table 1.

Postprocessing techniques include reformatting of axial image data for coronal, sagittal, and maximum intensity projections.

Multiplanar reformatting of axial image data allows excellent demonstration and characterization of enteric and

Table 1 Summary of the technique

1. Withhold all oral intake $4 \mathrm{~h}$ prior to examination

2. $1.5-2 \mathrm{~L}$ of oral neutral contrast ( $20 \%$ mannitol) given over $45 \mathrm{~min}$, last $200-250 \mathrm{~mL}$ ingested on table prior to scanning for gastric distension

3. $20 \mathrm{mg}$ Buscopan administered intravenously (IV) prior to scanning

4. $1.5 \mathrm{~mL} / \mathrm{kg}$ of lohexol ( $\max 150 \mathrm{~mL}$ ) administered IV at $4 \mathrm{~mL} / \mathrm{s}$ via 18-gauge cannula using automated power injector

5. Scanning is performed from diaphragm to symphysis pubis. Images acquired at $45 \mathrm{~s}$ post-IV contrast administration

6. 128-slice multiple detector computed tomography (MDCT) scanner Philips Ingenia

7. Slice thickness $2 \mathrm{~mm}$, reconstruction interval $0.75 \mathrm{~mm}$ extraenteric abnormalities. ${ }^{17}$ Maximum intensity projection images are useful particularly for visualizing the mesenteric vasculature.

\section{Intestinal Tuberculosis}

The incidence of extrapulmonary TB is 15 to $20 \%$, with $3 \%$ affecting the abdomen including the small bowel. Abdominal $\mathrm{TB}$ is the sixth most common extrapulmonary site of involvement. Only $15 \%$ of patients with abdominal TB have evidence of pulmonary disease, and chest radiography may be normal in 50 to $65 \%$ of these patients. ${ }^{5,18}$

ITB can be divided into three categories-ulcerative, hypertrophic, and ulcerohypertrophic-with the ulcerative type being the most common. Manifestations depend on the host's immune system. The ulcerative form occurs in patients with reduced immune response, where healing often results in the formation of fibrotic strictures, especially if the ulcers are deep and circumferential. The hypertrophic form consists of bowel wall thickening with scarring, fibrosis, and a rigid mass-like appearance that mimics that of malignancies. The ulcero-hypertrophic form is a subtype with a combination of the features of the ulcerative and hypertrophic forms. ${ }^{19}$

Imaging in the form of barium studies were the initial investigation for intestinal TB, but in the past decade, CT scan and, recently, CTE have almost replaced barium studies due to a better depiction of mural and extraintestinal involvement.

Abdominal tuberculosis may affect any part of bowel from the duodenum to rectum, but the most frequent site of ITB is ileocecal area ( $90 \%$ in case of gastrointestinal TB). The sites of involvement in descending order of frequency are the ileocecal junction, followed by the ileum, caecum, ascending colon, jejunum, rest of the colon, rectum, duodenum, and stomach. ${ }^{20}$

Peritoneal TB is the most common form of abdominal TB and involves alone or in combination with the peritoneal cavity, mesentery, and omentum. Three types of peritoneal TB are described ${ }^{21,22}$ : wet type with ascites or pockets of loculated fluid ( - Figs. 1 and 2); dry type with bulky mesenteric thickening and lymph adenopathy ( - Fig. 3); and third type with mass formation due to omental thickening that may be mistaken for a tumor. ${ }^{21}$

Active ileocecal disease is characterized by circumferential wall thickening of terminal ileum, ileocecal junction, and cecum with narrowed lumen (-Figs. 4-6). Dilatation of the proximal bowel segment may be seen. Another predictor of active inflammation is enhancement of mucosa or the entire wall. Intestinal wall thickening is usually homogeneous without stratification. Wall stratification seen in CD results from contrast enhancement of mucosa and muscularis, with hypodense edema of submucosa causing a layered appearance.

Healing results in short-segment strictures that are seen as short segments of wall thickening without wall enhancement or stratification with proximal bowel dilatation. ${ }^{20}$ Ileocecal valve may also become scarred with stricture and subsequent dilatation of the terminal ileum, which rarely may become patulous with loss of valve function. Usually, 

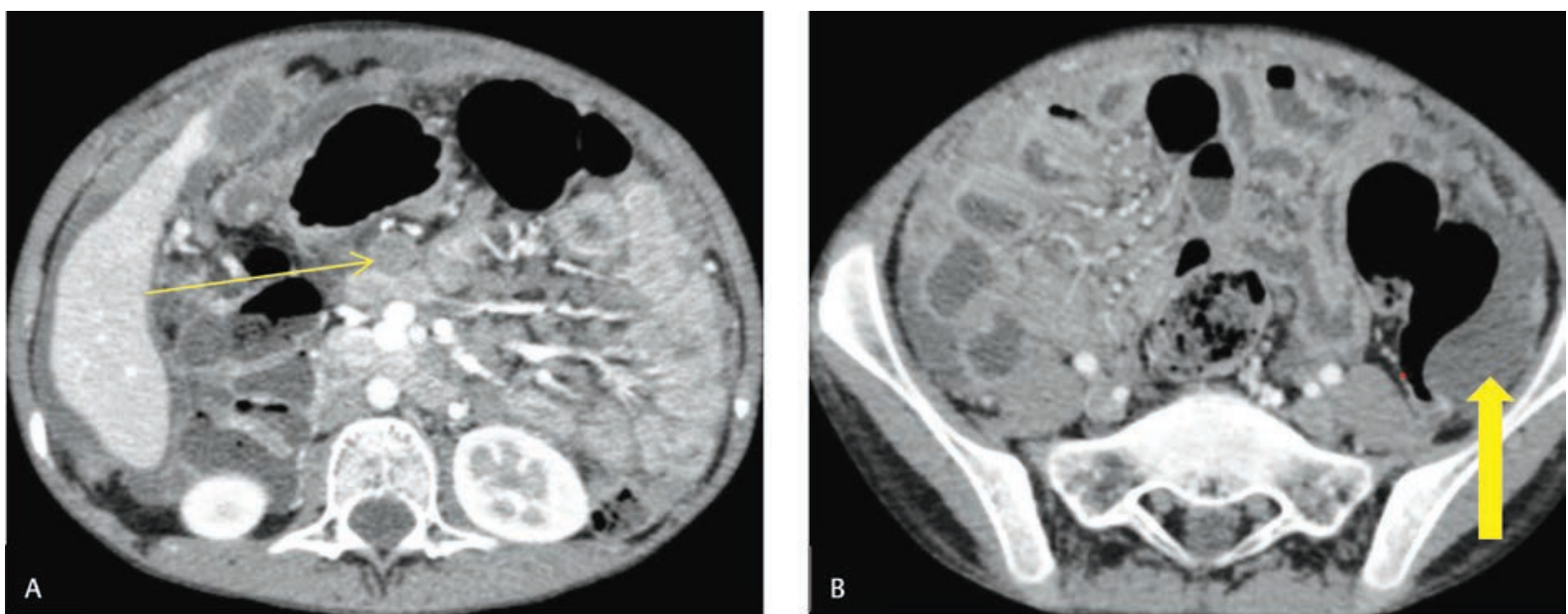

Fig. 1 Axial (A) and (B) CTE images in a 19-year-old-male patient with wet tubercular peritonitis who presented with abdominal distension and fever for 1.5 months, showing mesenteric nodes (thin arrow), ascites (thick arrow), and peritoneal enhancement.

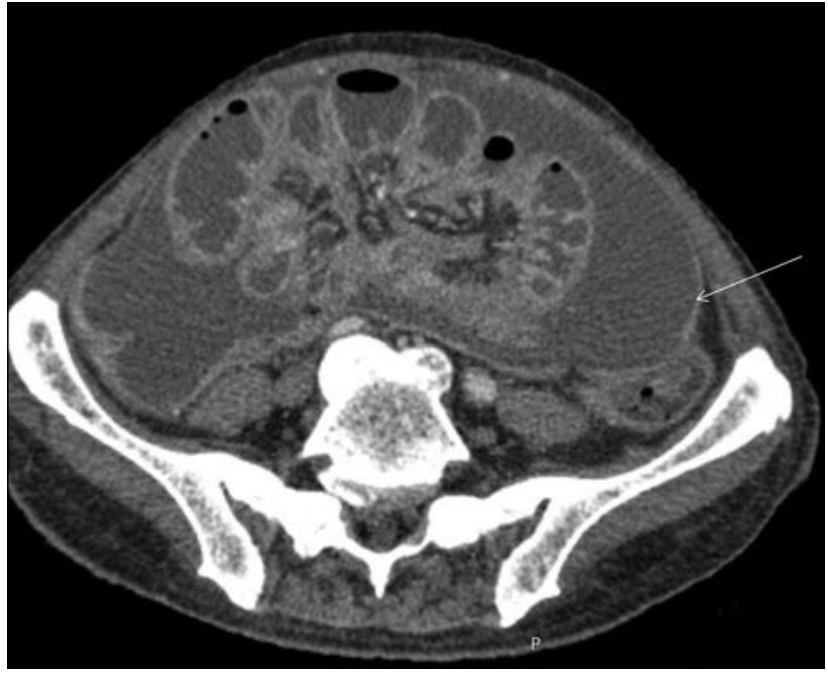

Fig. 2 Axial CTE image in a 30-year-old man with TB peritonitis showing enhancing peritoneum (arrow) encasing small bowel loops giving a clustered centrally in a cocoon-like appearance. the segment of involvement is single in ITB, infrequently multiple segments of involvement may also be seen when differentiation from $\mathrm{CD}$ is difficult. Isolated segmental colonic involvement may be seen in $10 \%$ of abdominal tuberculosis, with sigmoid, ascending, and transverse colon being common sites.

Other complications include vascular complications, intussusception, and obstruction of the small bowel. ${ }^{20}$

Extraintestinal changes include mesenteric nodal enlargement that may occur as discrete nodes or conglomerate nodal masses. Enlarged nodes are often necrotic, which helps in making an accurate diagnosis ( - Fig. 7). On healing, the nodes may disappear or may show calcification. Perienteric and mesenteric fat stranding is uncommon. Omental or peritoneal thickening may be seen with omentum showing nodularity or smudgy pattern of enhancement. There may be associated abdominal cocoon ( - Fig. 2), developing due to thin film of fibrosis encasing the bowel loops that appear clumped. This is seen on CTE or MRE as an area of clumped, often dilated, small
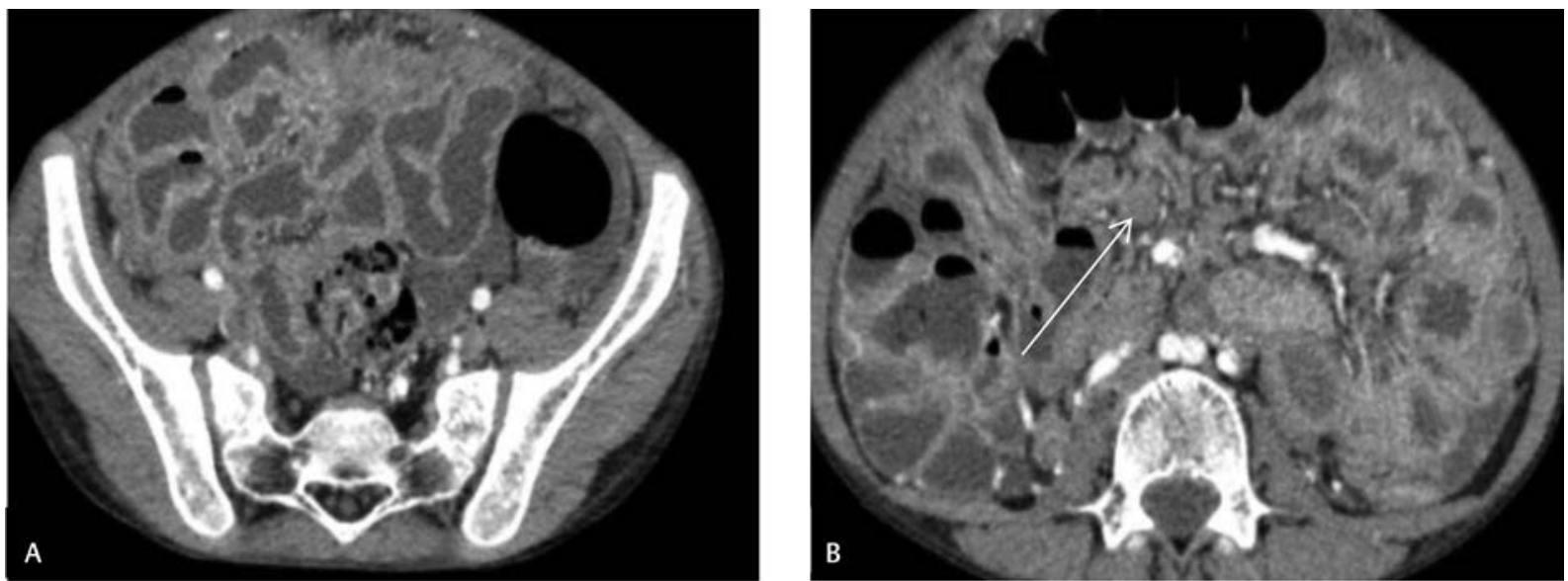

Fig. 3 Axial (A) and (B) CTE images in a 44-year-old man with abdominal discomfort and low-grade fever showing mesenteric nodes (thin arrow) and peritoneal enhancement-DRY tubercular peritonitis. 

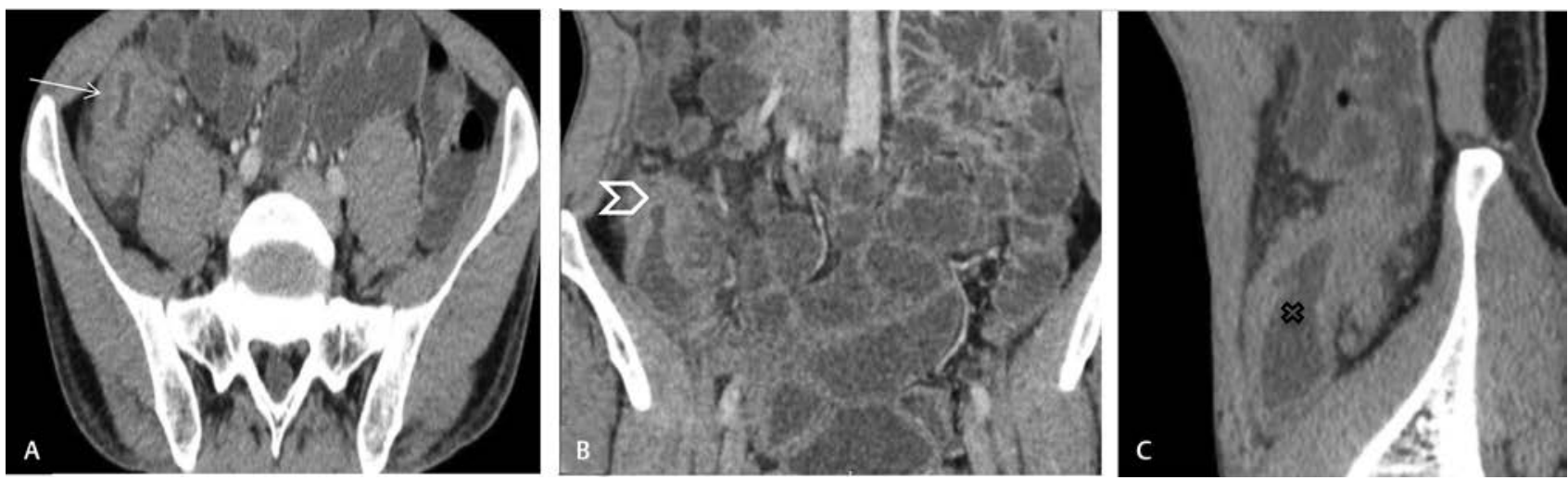

Fig. 4 Axial (A), coronal (B), and sagittal (C) CTE images in a 30-year-old patient with ITB showing gross thickening of cecum (arrow) ileocecal junction (arrowhead) with dilatation of terminal ileum (X).
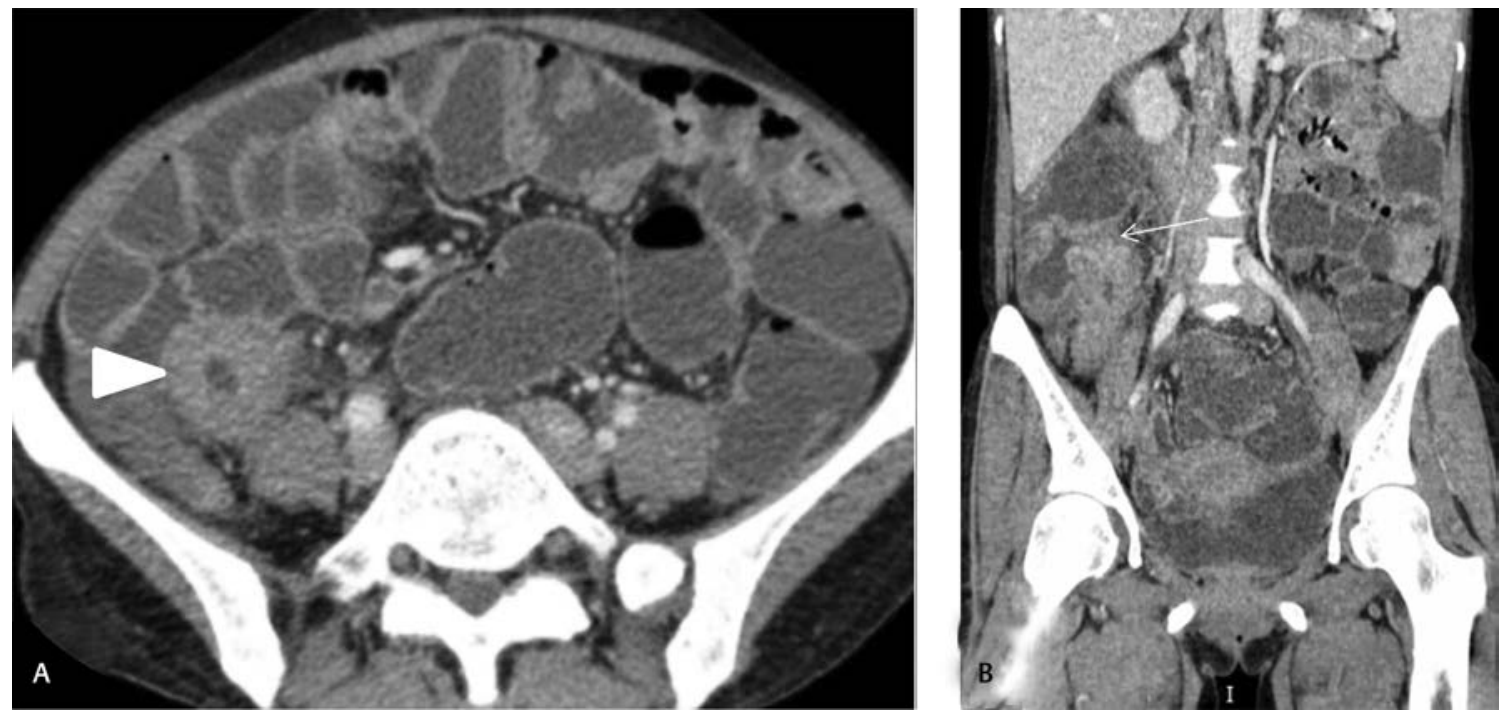

Fig. 5 Axial (A) and coronal (B) CTE images in a 26-year-old woman with low-grade fever and weight loss showing thickening and contraction of cecum (arrowhead) with pericecal fat stranding and gross thickening of ileocecal valve (arrow) consistent with ITB.

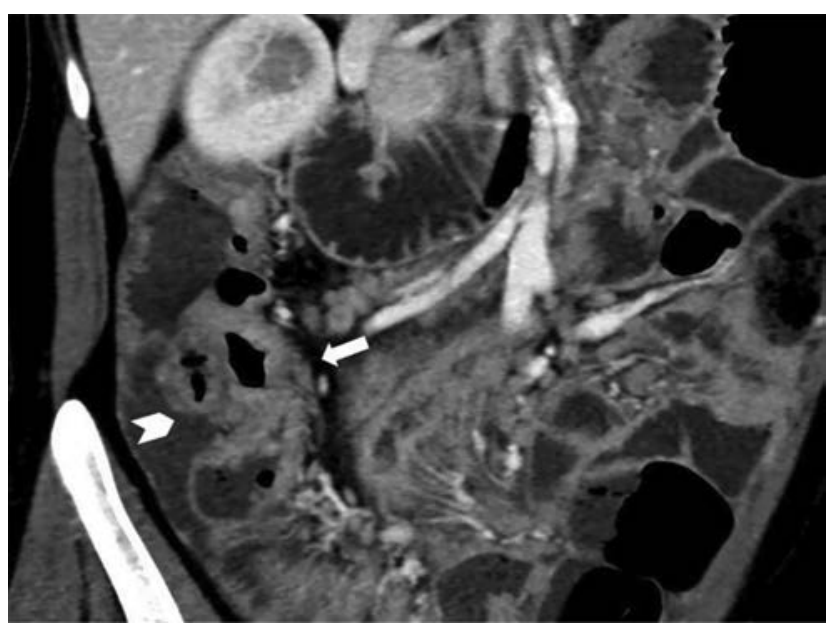

Fig. 6 lleocecal Koch's: Oblique coronal reconstruction through the abdomen in the venous phase of a 25-year-old woman with fever and weight loss shows a contracted cecum (arrowhead) and significantly thickened, heterogeneously enhancing terminal ileum and ileocecal junction without wall stratification (arrow) suggestive of TB. Necrotic nodes are seen just above the arrowhead. Ascitis with tiny peritoneal nodules are seen just lateral to the arrowhead. bowel loops with thin hypodense or hypointense capsule around it. In long-standing cases, there may be proliferation of surrounding fat, although infrequently. Associated involvement of other organs such as the liver, spleen, or peritoneum also helps in making a diagnosis ( - Fig. 8)..$^{23}$

\section{Crohn's Disease}

$\mathrm{CD}$ is characterized by chronic, transmural, often granulomatous, and intestinal inflammation. The small bowel is involved in almost $80 \%$ of the cases, with the ileocecal region affected in $50 \% .{ }^{24}$ Enteric involvement of CD tends to be transmural, segmental, and usually discontinuous also known as skip lesions ${ }^{16}$ ( - Fig. 9). Small bowel disease is multifocal with areas of different activity, some areas with acute inflammatory, and others with fibrostenosing disease ( - Fig. 10).

$C D$ has been classified into four stages that help in planning therapy $^{25}$ : (1) active inflammatory, (2) fibrostenotic, (3) penetrating, and (4) reparative or regenerative subtypes. Active inflammation shows various features on imaging, as ulceration and mucosal enhancement. Fibrostenotic disease suggests a 

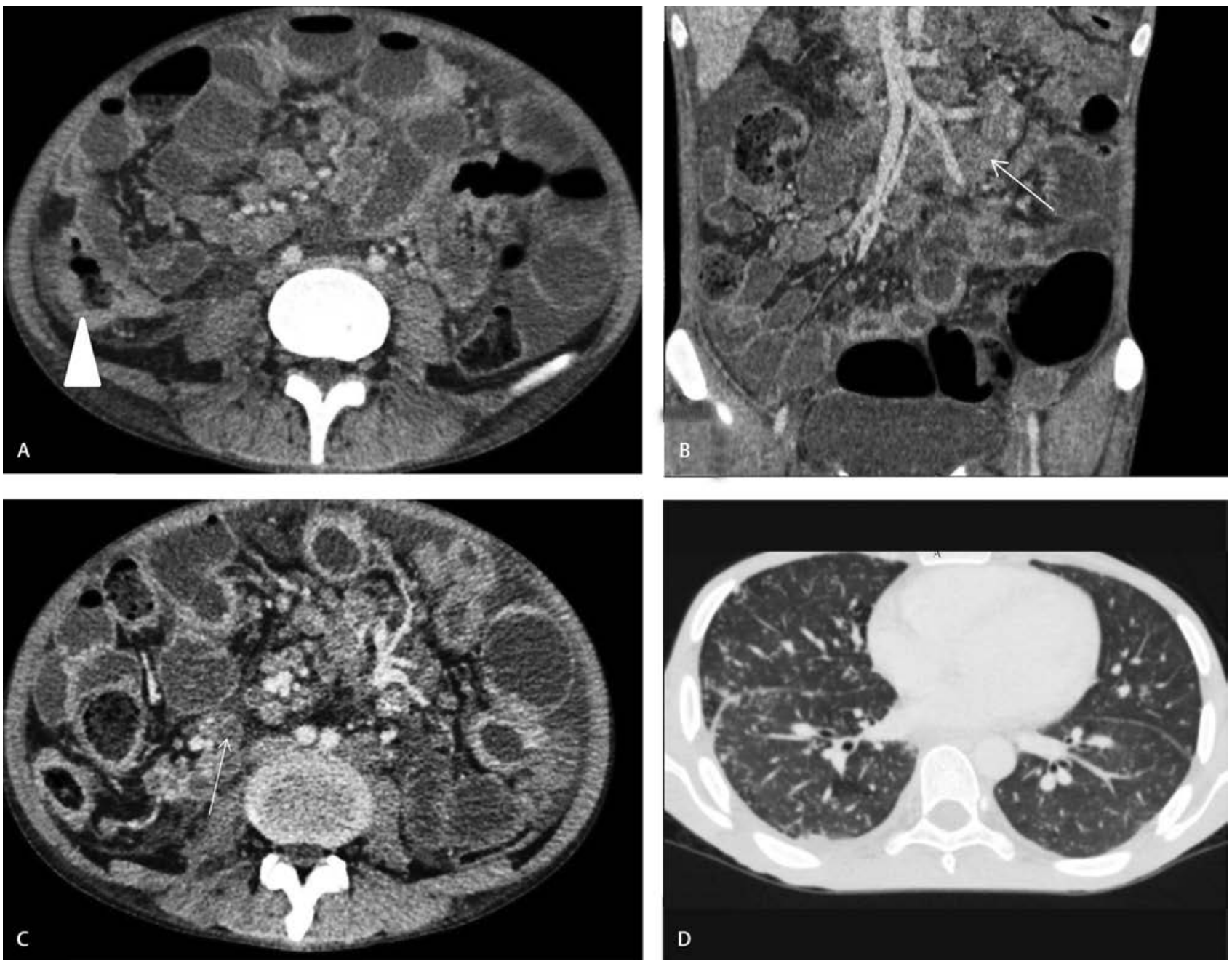

Fig. 7 Axial (A), coronal (B), and axial (C) CTE images in a 38-year-old man with ileocecal TB showing thickening of cecum and ileocecal junction (arrowhead) with enlarged necrotic nodes (arrows) and axial (D) CT chest image shows multiple centrilobular nodules in bilateral lung fields giving a tree in bud apprearance
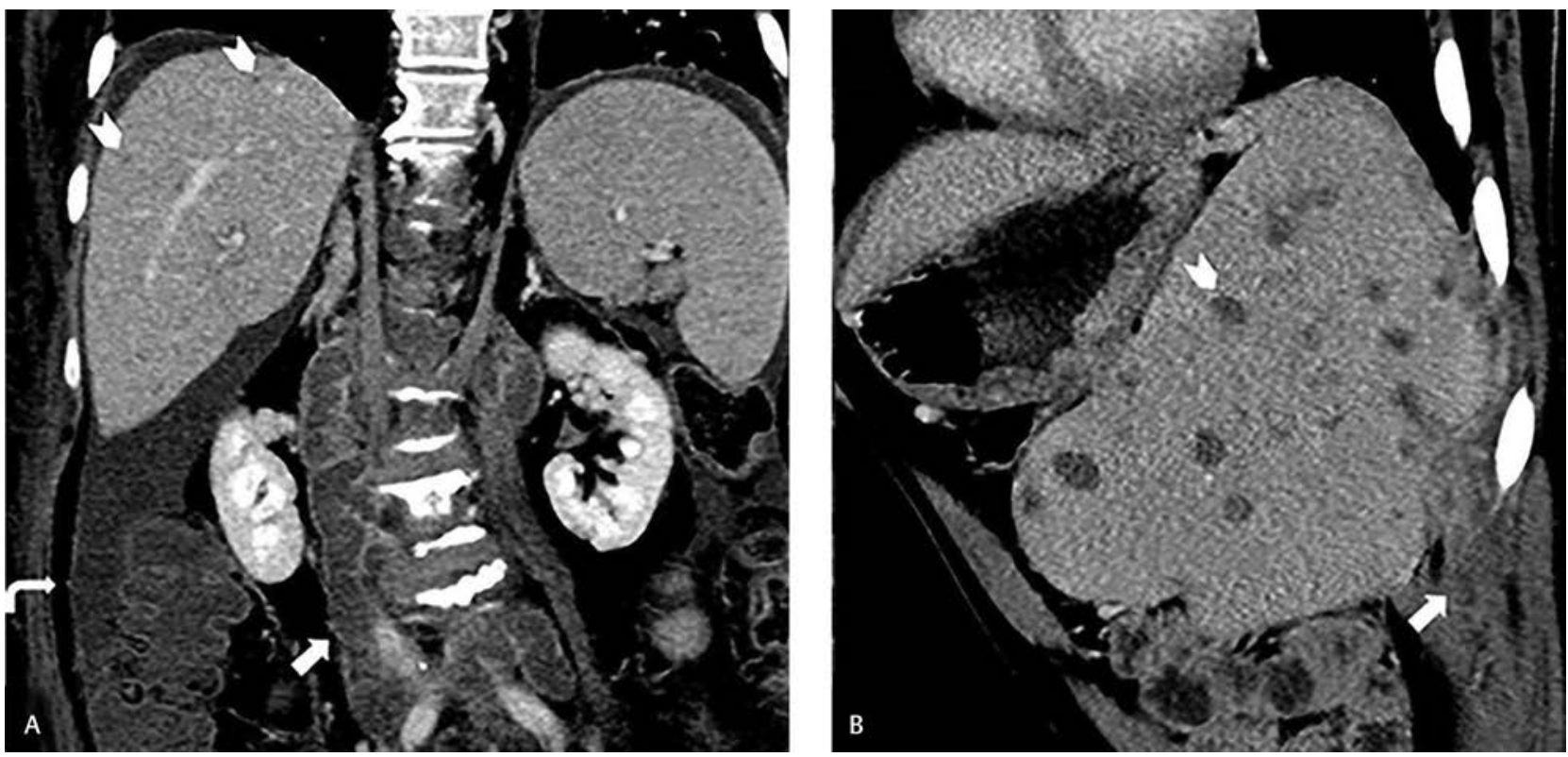

Fig. 8 Hepatic perit spleen Koch's: Oblique coronal reconstruction through the abdomen in the venous phase of a 68-year-old diabetic man with pulmonary TB. (A) Several tiny hepatic nodules (arrowheads), peritoneal thickening (curved arrow), and coalescent necrotic retroperitoneal nodes (straight arrow). (B) Multiple small splenic hypodense nodules (arrowhead). Some of these nodules have coalesced to form a sinus leading to the perisplenic region and lateral abdominal wall (arrow). 

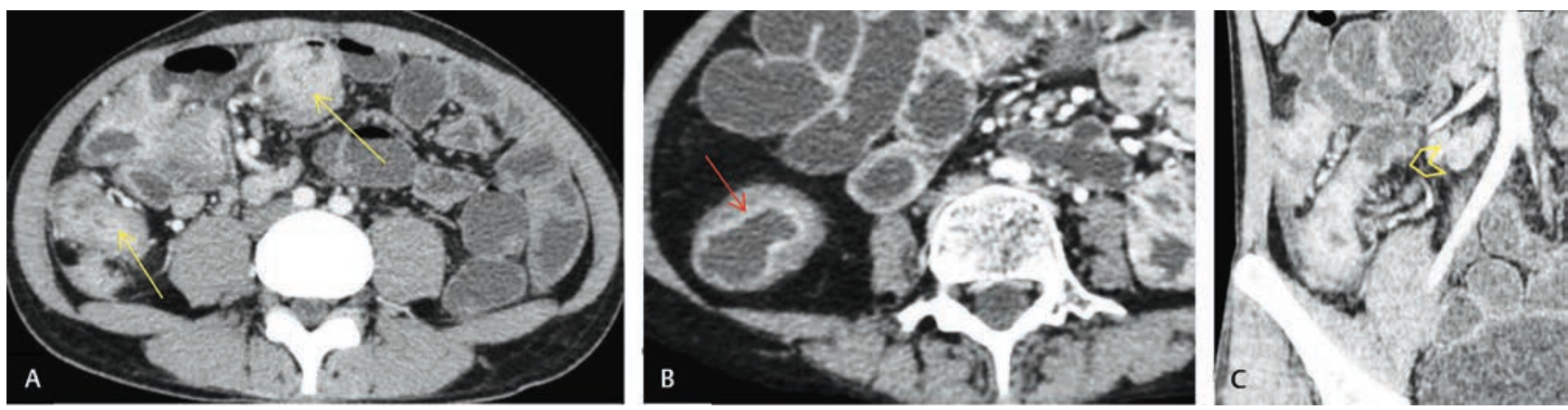

Fig. 9 Active Crohn's disease in a 45-year-old woman. Axial (A), axial (B), and coronal (C) CTE section Multifocal involvement mucosal hyperenhancement (red arrow) and mural stratification (yellow arrow) of the terminal ileum. Coronal CTE image shows mesenteric hypervascularity (arrowheads) adjacent to the involved bowel segment, indicating active Crohn's disease.
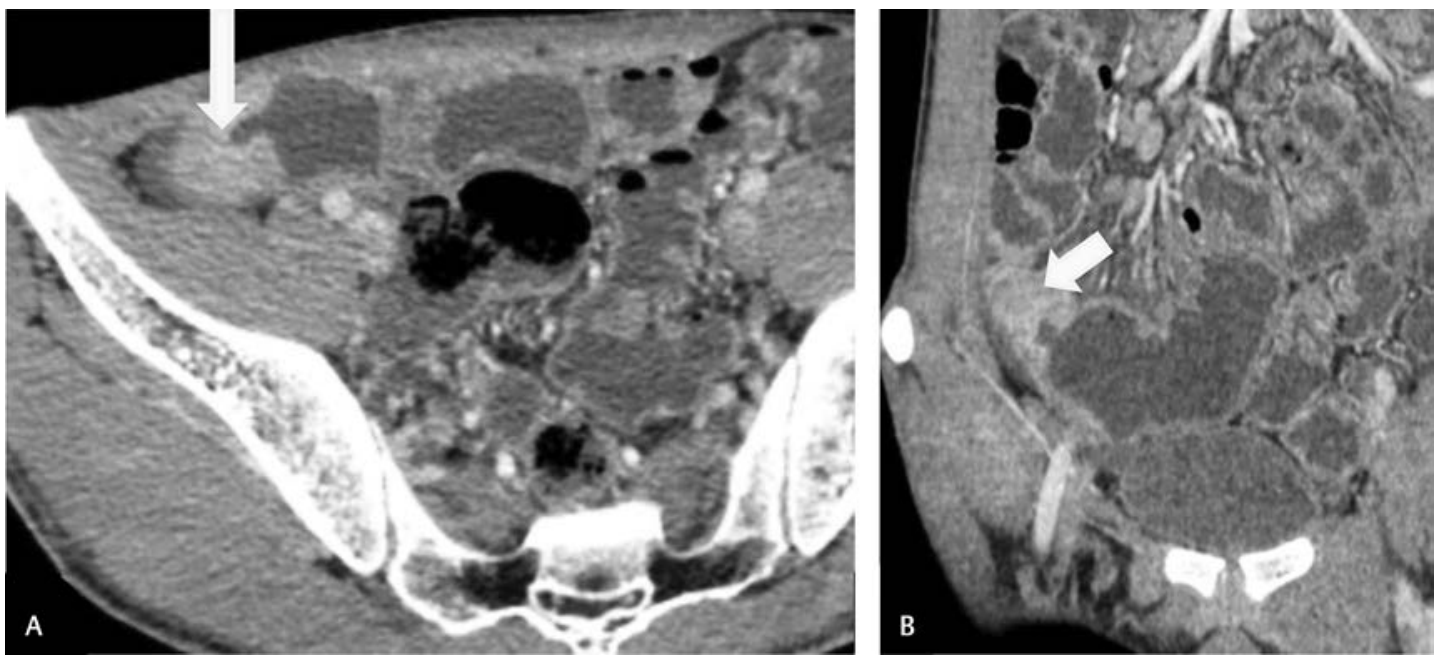

Fig. 10 Fibrostenosing Crohn's disease in a 32-year-old man. Axial and coronal CTE image shows a segmental stricture involving proximal ileal loop. Homogenous mural thickening is seen at the strictured segment without mural hyperenhancement, suggesting fibrostenotic disease (arrow).
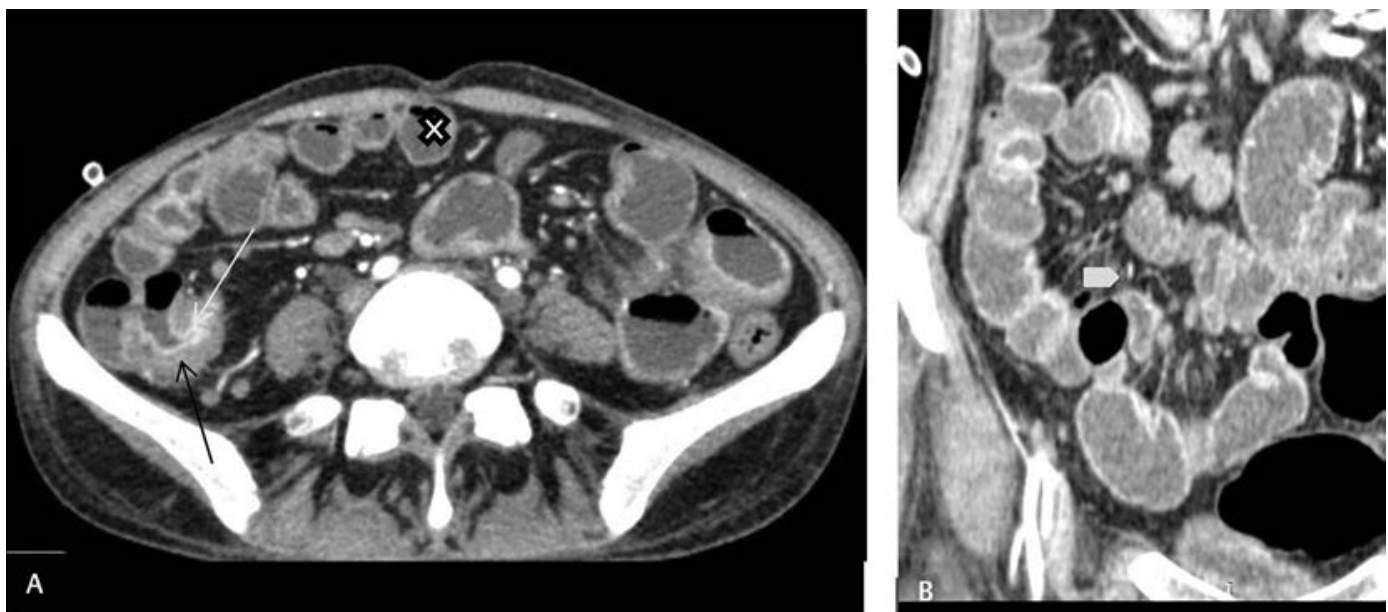

Fig. 11 Active Crohn's disease in a 20-year-old man. Axial CTE section shows mucosal hyperenhancement (black arrow) and mural stratification (white arrow) of the terminal ileum, an appearance that contrasts markedly with that of nondiseased ileal segments (X). Axial (A) and coronal (B) CTE image shows mesenteric hypervascularity (comb sign) (arrowhead) adjacent to the involved bowel segment, indicating active Crohn's disease.

healing phase due to collagen deposition and stricture formation. Penetrating disease occurs due to the extension of deep ulcers, resulting in extraintestinal inflammation, abscesses, sinuses, and fistulas. Often, multiple stages coexist in the same patient or bowel segment. ${ }^{25}$ Similar to ITB, the ileocecal region is the most common site of involvement. Involvement of multiple segments with normal intervening bowel segment is typically seen, but this alone may not be specific. 

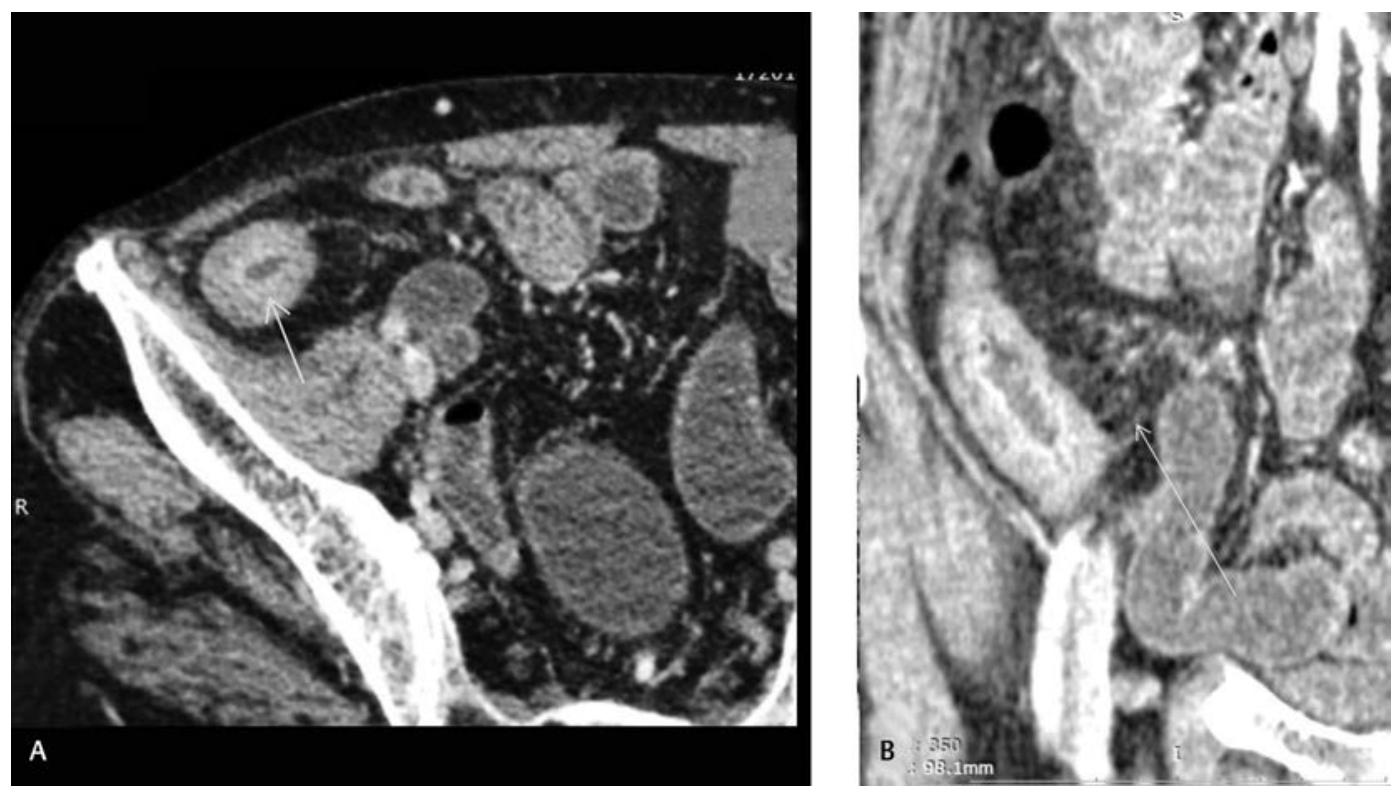

Fig. 12 Axial CTE section shows mucosal hyperenhancement and mural stratification of the terminal ileum. Axial (A) and coronal (B) CTE image shows mesenteric hypervascularity (arrow), comb sign, adjacent to the involved bowel segment indicating active Crohn's disease.

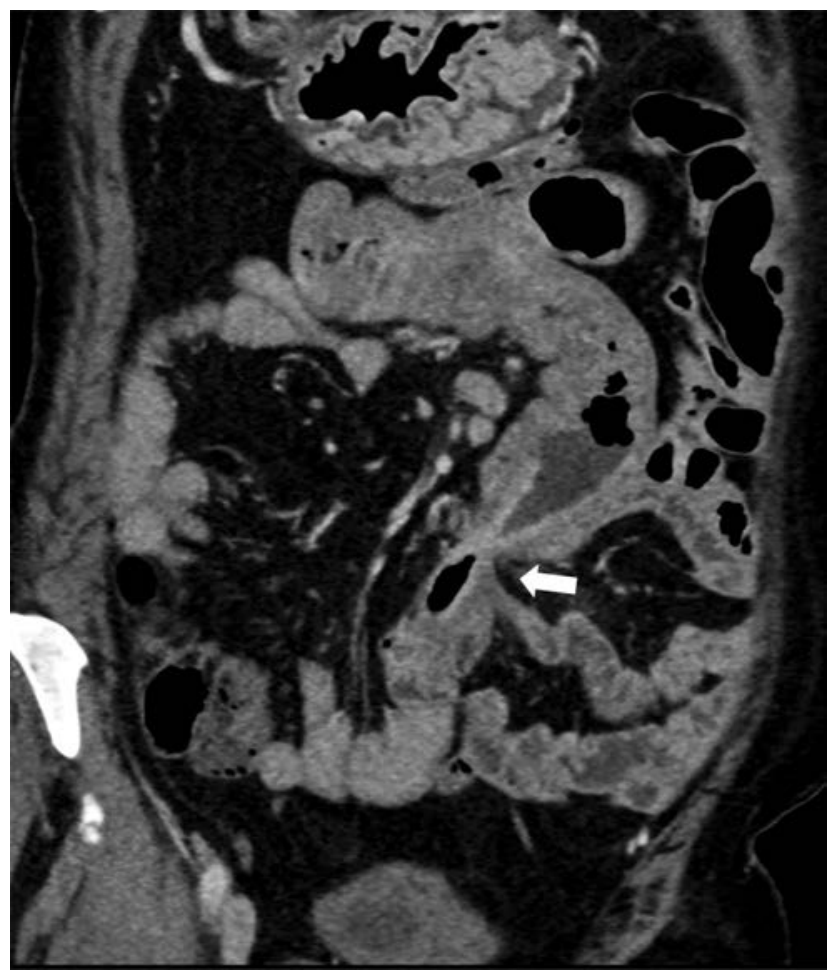

Fig. 13 Crohn's stricture: Oblique coronal reconstruction through the abdomen in the venous phase of a 56-year-old man, with symptoms of recurrent subacute intestinal obstruction showing a stricture (arrow) with wall stratification and intense enhancement of the mucosa suggestive active inflammation.

CD has a variety of appearances at CTE depending on disease activity and associated complications such as fistula or abscess. On CTE, enteric findings such as mural hyperenhancement, bowel wall thickening, mural stratification and extraenteric findings such as engorged vasa recta ("comb sign"), ${ }^{26}$ and increased attenuation of the mesenteric fat are features of active inflammatory small bowel $C D^{26,27}$ (-Figs. 11-13). Among these findings, combination of mural hyperenhancement and bowel wall thickening is the most sensitive CTE findings suggesting the active inflammatory CD.

Mural enhancement is the most sensitive indicator of active $\mathrm{CD}^{28}$; therefore, bowel loops with similar distension should be compared as both the jejunum and normal collapsed loops may demonstrate regions of higher attenuation simulating enhancement.

A mural attenuation threshold of $109 \mathrm{HU}$ and an abnormal to normal loop enhancement ratio of $>1.3$ have been used to objectively correlate mural hyperenhancement and bowel wall thickness with disease activity on CTE and highly correlated with histologic findings of active disease. Visual assessment, however, presents higher specificity than quantitative measurements. $^{29}$

The term mural stratification denotes the visualization of bowel wall layers at CT after administration of IV contrast) ${ }^{28,30,31}$ ( - Fig. 12). Bilaminar mural stratification refers to mucosal hyperenhancement and decreased intramural attenuation, and trilaminar mural stratification refers to alternating areas of high and low attenuation due to mucosal and serosal hyperenhancement and low intramural attenuation. The low intramural attenuation can represent edema, inflammatory infiltrate, or fat. Mural stratification due to intramural edema is more indicative of active disease compared with a homogenously enhanced wall, ${ }^{32}$ whereas the presence of intramural fat indicates chronic process. ${ }^{27}$

In active $\mathrm{CD}$, increased attenuation of the mesenteric fat is often seen due to edema or prominence of vasa recta. Prominence of the vasa recta is known as the "comb sign." ${ }^{26,33}$ This sign, along with increased mesenteric fat attenuation, is the most specific CT feature of active CD. ${ }^{34}$ Findings suggestive of chronicity in CD include submucosal fat deposition, pseudosacculation, surrounding fibrofatty proliferation, and fibrotic 
strictures. Inflammatory involvement of the mesenteric border of the affected bowel segment with associated asymmetric fibrosis and pseudosacculation of the antimesenteric border is a hallmark. ${ }^{16}$

The transmural inflammation with increased intraluminal pressure proximal to the site of strictures may lead to extension of the inflammatory process across the serosal surface into the adjacent mesentery or structures, resulting in extraenteric complications as fistula, sinus tract, and abscess. CTE has an important role in the evaluation of extraenteric complications of $C D^{25,35}$ (-Figs. 14 and $\mathbf{1 5}$ ).

CTE has high sensitivity for the detection of bowel strictures occurring as a complication of CD. Reversible strictures are characterized by mucosal hyperenhancement, mural stratification, fat stranding, and engorgement of the vasa recta; however, transmural fibrosis may result in a lack of enhancement and loss of stratification..$^{16}$ It is important to differentiate between active and fibrotic strictures ( - Fig. 8) because the former warrants medical management whereas the latter may require surgical intervention. ${ }^{35}$

Extraenteric findings such as cholelithiasis, urolithiasis, and sacroiliitis are also picked up on $\mathrm{CT}^{36}$
Radiologic features are helpful in differentiating ITB from CD. ${ }^{1,37}$ These differences are presented in - Table 2 .

Radiologic investigations provide useful clues to aid diagnosis, but their major role is in assessing the extent of the disease. $^{38}$

Endoscopy plays an important role in diagnosis. ${ }^{39,40}$ Apart from visual inspection, mucosal biopsy can be obtained for histopathology, culture, and molecular tests. CD patients usually have longitudinal ulcers, cobblestone appearance of mucosa, and anorectal involvement. ${ }^{41}$ Transverse ulcers, patulous ileocecal valve, and involvement of fewer of colonic segments are commoner in ITB.

ITB and CD are both chronic granulomatous diseases with subtle histologic differences between them. Histologic features suggesting ITB include confluent granulomas, multiple granulomas, large granuloma size, bands of epithelioid histiocytes lining ulcers, submucosal granulomas, and disproportionate submucosal inflammation, that is, submucosal inflammation that significantly exceeds mucosal inflammation. Although caseation and necrosis in granulomas or positive stain for acid-fast Bacillus (AFB) is virtually diagnostic for ITB, the problem is the poor yield of endoscopic sampling,
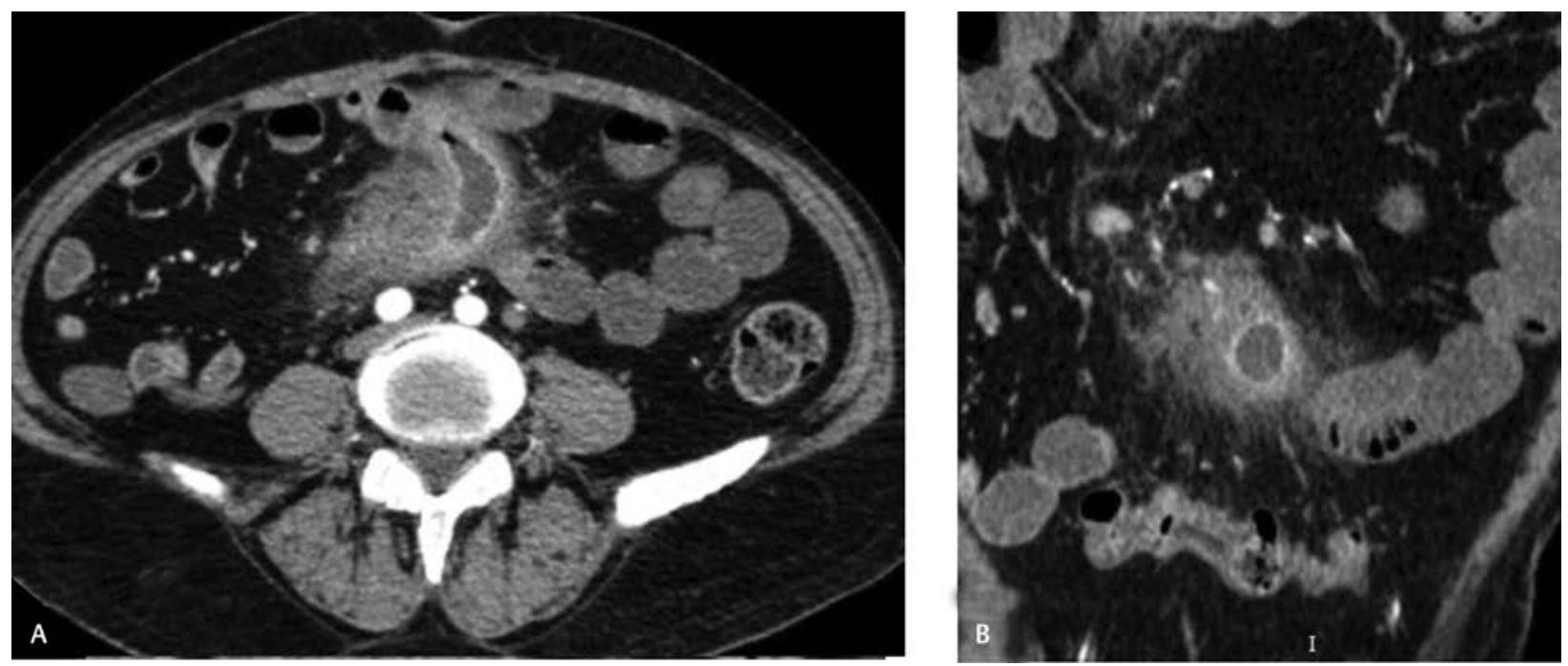

Fig. 14 Crohn's disease in a 34-year-old woman. (A) Axial and (B) coronal CTE image shows enteroenteric fistula involving ileal loops (arrow) with adjacent fat stranding.

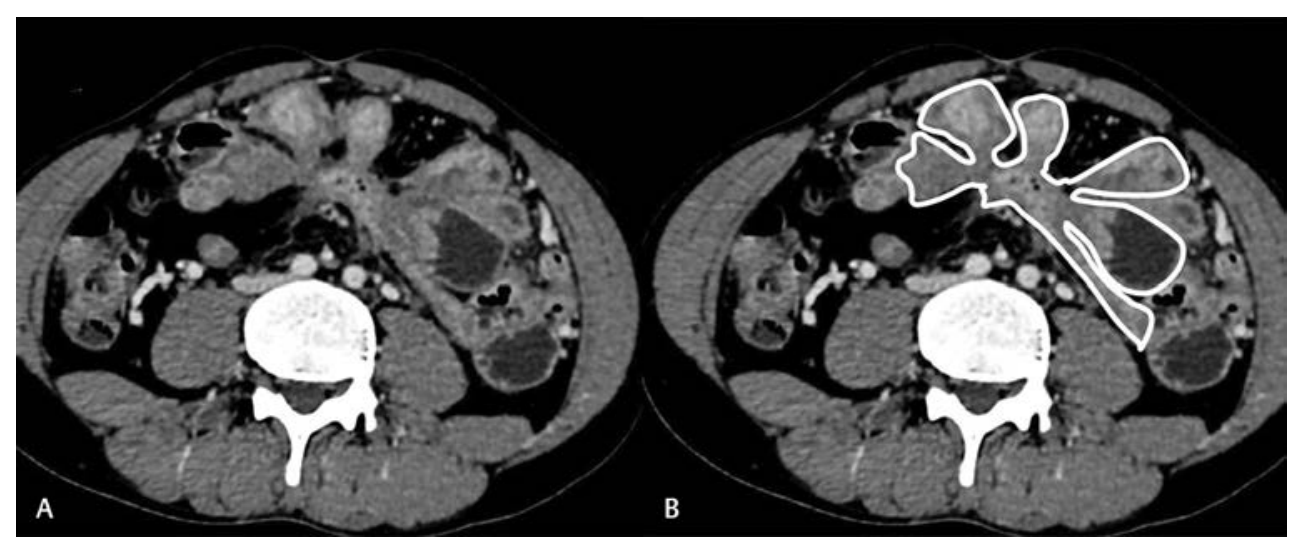

Fig. 15 Fistulizing Crohn's: axial sections through the abdomen in the venous phase of a 43-year-old man show a radiating pattern of fistulae connecting adjacent small bowel loops in panel A. The outline of the fistulae has been drawn in panel B. 
Table 2 Differentiating features of ITB and CD

\begin{tabular}{|l|l|l|}
\hline Features & ITB & CD \\
\hline $\begin{array}{l}\text { Site of } \\
\text { involvement }\end{array}$ & $\begin{array}{l}\text { IC Jith terminal } \\
\text { ileum }\end{array}$ & Terminal ileum \\
\hline $\begin{array}{l}\text { Length of } \\
\text { involvement }\end{array}$ & Short segment & Long segment \\
\hline Wall thickness & $<6 \mathrm{~mm}$ & $>6 \mathrm{~mm}$ \\
\hline Skip lesions & Uncommon & Common \\
\hline $\begin{array}{l}\text { Mural hyperen- } \\
\text { hancement }\end{array}$ & Rare & In active CD \\
\hline $\begin{array}{l}\text { Mural } \\
\text { stratification }\end{array}$ & Uncommon & Common \\
\hline Interbowel fistula & Rare & Common \\
\hline $\begin{array}{l}\text { Mesenteric } \\
\text { abscess }\end{array}$ & Rare & Common \\
\hline $\begin{array}{l}\text { Increased mesen- } \\
\text { teric vascularity }\end{array}$ & Uncommon & $\begin{array}{l}\text { Common (comb } \\
\text { sign) }\end{array}$ \\
\hline Ascites & Frequent & Uncommon \\
\hline $\begin{array}{l}\text { Peritoneal } \\
\text { thickening }\end{array}$ & Often associated & Uncommon \\
\hline $\begin{array}{l}\text { Omental caking, } \\
\text { nodularity }\end{array}$ & Frequent & Rare \\
\hline $\begin{array}{l}\text { Mesenteric nodes } \\
\text { necrotic }\end{array}$ & Large $>1$ cm), \\
\hline homogenous \\
\hline Abrevions:cD Crs
\end{tabular}

Abbreviations: CD, Crohn's disease; IC], ileocolic junction; ITB, intestinal tuberculosis.

which is diagnostic in $<30 \%$ of cases. Features seen more frequently in $\mathrm{CD}$ include microgranulomas, nonconfluent granulomas, single granulomas as the only foci of granulomatous inflammation, and architectural distortion distant from granulomatous inflammation. ${ }^{1}$

\section{Conclusion}

CTE is a valuable tool for differentiating ITB from CD. It helps in making a diagnosis, defining the extent of disease, and assessing the presence of active inflammation and complications. Although overlapping findings occur with ITB, a combination of findings helps us differentiate between the two.

\section{Conflict of Interest}

None declared.

\section{References}

1 Pulimood AB, Amarapurkar DN, Ghoshal U, et al. Differentiation of Crohn's disease from intestinal tuberculosis in India in 2010. World J Gastroenterol 2011;17(4):433-443

2 Tandon R, Ahuja V. Differentiating intestinal tuberculosis and Crohn's disease. In: Jewell DP, Tandon R, Ahuja V, eds. Inflammatory Bowel Disease. New Delhi, India: Macmillan Medical Communications; 2014:41-61

3 Ahuja V, Tandon RK. Inflammatory bowel disease: the Indian augury. Indian J Gastroenterol 2012;31(6):294-296

4 Ahuja V, Tandon RK. Inflammatory bowel disease in the Asia-Pacific area: a comparison with developed countries and regional differences. J Dig Dis 2010;11(3):134-147
5 Sharma SK, Mohan A. Extrapulmonary tuberculosis. Indian J Med Res 2004;120(4):316-353

6 Das K, Ghoshal UC, Dhali GK, Benjamin J, Ahuja V, Makharia GK. Crohn's disease in India: a multicenter study from a country where tuberculosis is endemic. Dig Dis Sci 2009; 54(5):1099-1107

7 Makanjuola D. CT and barium features of gastrointestinal and peritoneal tuberculosis. Saudi J Gastroenterol 1997;3(3):133-139

8 Bernstein CN, Boult IF, Greenberg HM, van der Putten W, Duffy G, Grahame GR. A prospective randomized comparison between small bowel enteroclysis and small bowel follow-through in Crohn's disease. Gastroenterology 1997; 113(2):390-398

9 Nagi B, Lal A, Kochhar R, Bhasin DK, Thapa BR, Singh K. Perforations and fistulae in gastrointestinal tuberculosis. Acta Radiol 2002;43(5):501-506

10 Maglinte DD, Sandrasegaran K, Lappas JC, Chiorean M. CT enteroclysis. Radiology 2007;245(3):661-671

11 Fletcher JG. CT enterography technique: theme and variations. Abdom Imaging 2009;34(3):283-288

12 Siddiki HA, Fidler JL, Fletcher JG, et al. Prospective comparison of state-of-the-art MR enterography and CT enterography in small-bowel Crohn's disease. Am J Roentgenol 2009;193(1):113-121

13 Young BM, Fletcher JG, Booya F, et al. Head-to-head comparison of oral contrast agents for cross-sectional enterography: small bowel distention, timing, and side effects. J Comput Assist Tomogr 2008;32(1):32-38

14 Elsayes KM, Al-Hawary MM, Jagdish J, Ganesh HS, Platt JF. CT enterography: principles, trends, and interpretation of findings. Radiographics 2010;30(7):1955-1970

15 Ilangovan R, Burling D, George A, Gupta A, Marshall M, Taylor SA. CT enterography: review of technique and practical tips. $\mathrm{Br}$ J Radiol 2012;85(1015):876-886

16 Tochetto S, Yaghmai V. CT enterography: concept, technique, and interpretation. Radiol Clin North Am 2009;47(1):117-132

17 Jaffe TA, Martin LC, Miller CM, et al. Abdominal pain: coronal reformations from isotropic voxels with 16-section CTreader lesion detection and interpretation time. Radiology 2007;242(1):175-181

18 Pereira JM, Madureira AJ, Vieira A, Ramos I. Abdominal tuberculosis: imaging features. Eur J Radiol 2005;55(2):173-180

19 Acharya SK, Tandon BN. Abdominal tuberculosis. In: Watters D, Kiire C, eds. Gastroenterology in the Tropics and Subtropics: A Practical Approach. 10th ed. London and Basingstoke, England: Macmillan Education; 2005:85-102

20 Gulati MS, Sarma D, Paul SB. CT appearances in abdominal tuberculosis. A pictorial essay. Clin Imaging 1999;23(1):51-59

21 Hanson RD, Hunter TB. Tuberculous peritonitis: CT appearance. AJR Am J Roentgenol 1985;144(5):931-932

22 Thoeni RF, Margulis AR. Gastrointestinal tuberculosis. Semin Roentgenol 1979;14(4):283-294

23 Sharma R, Kumble S, Ahuja V. Intestinal tuberculosis vs Crohn's disease clinical and radiological recommendations. Indian J Radiol Imaging 2016;26(2):161-172

24 Stange EF, Travis SP, Vermeire S, et al; European Crohn's and Colitis Organisation. European evidence based consensus on the diagnosis and management of Crohn's disease: definitions and diagnosis. Gut 2006;55(Suppl 1):i1-i15

25 Maglinte DD, Gourtsoyiannis N, Rex D, Howard TJ, Kelvin FM. Classification of small bowel Crohn's subtypes based on multimodality imaging. Radiol Clin North Am 2003; 41(2):285-303

26 Meyers MA, McGuire PV. Spiral CT demonstration of hypervascularity in Crohn disease: "vascular jejunization of the ileum" or the "comb sign. Abdom Imaging 1995;20(4):327-332 
27 Paulsen SR, Huprich JE, Fletcher JG, et al. CT enterography as a diagnostic tool in evaluating small bowel disorders: review of clinical experience with over 700 cases. Radiographics 2006;26(3):641-657

28 Booya F, Fletcher JG, Huprich JE, et al. Active Crohn disease: CT findings and interobserver agreement for enteric phase CT enterography. Radiology 2006;241(3):787-795

29 Bodily KD, Fletcher JG, Solem CA, et al. Crohn disease: mural attenuation and thickness at contrast-enhanced CT enterography-correlation with endoscopic and histologic findings of inflammation. Radiology 2006;238(2):505-516

30 American College of Radiology. ACR Appropriateness Criteria. Reston, VA: American College of Radiology; 2005

31 Goldberg HI, Gore RM, Margulis AR, Moss AA, Baker EL. Computed tomography in the evaluation of Crohn disease. Am J Roentgenol 1983;140(2):277-282

32 Hara AK, Leighton JA, Heigh RI, et al. Crohn disease of the small bowel: preliminary comparison among CT enterography, capsule endoscopy, small-bowel follow-through, and ileoscopy. Radiology 2006;238(1):128-134

33 Madureira AJ. The comb sign. Radiology 2004;230(3):783-784

34 Colombel JF, Solem CA, Sandborn WJ, et al. Quantitative measurement and visual assessment of ileal Crohn's disease activity by computed tomography enterography: correlation with endoscopic severity and $\mathrm{C}$ reactive protein. Gut 2006;55(11):1561-1567

35 Vogel J, da Luz Moreira A, Baker M, et al. CT enterography for Crohn's disease: accurate preoperative diagnostic imaging. Dis Colon Rectum 2007;50(11):1761-1769

36 Smith EA, Dillman JR, Adler J, Dematos-Maillard VL, Strouse PJ. MR enterography of extraluminal manifestations of inflammatory bowel disease in children and adolescents: moving beyond the bowel wall. Am J Roentgenol 2012;198(1):W38-45

37 Zhao XS, Wang ZT, Wu ZY, et al. Differentiation of Crohn's disease from intestinal tuberculosis by clinical and CT enterographic models. Inflamm Bowel Dis 2014;20(5):916-925

38 Almadi MA, Ghosh S, Aljebreen AM. Differentiating intestinal tuberculosis from Crohn's disease: a diagnostic challenge. Am J Gastroenterol 2009;104(4):1003-1012

39 Amarapurkar DN, Patel ND, Rane PS. Diagnosis of Crohn's disease in India where tuberculosis is widely prevalent. World J Gastroenterol 2008;14(5):741-746

40 Shah S, Thomas V, Mathan M, et al. Colonoscopic study of 50 patients with colonic tuberculosis. Gut 1992;33(3):347-351

41 Lee YJ, Yang SK, Byeon JS, et al. Analysis of colonoscopic findings in the differential diagnosis between intestinal tuberculosis and Crohn's disease. Endoscopy 2006;38(6):592-597 